Kansas State University Libraries

New Prairie Press

\title{
BLOCKING IN PARTIAL DIALLEL CROSSES
}

D. R. Aneja

L.S. Kaushik

Follow this and additional works at: https://newprairiepress.org/agstatconference

Part of the Agriculture Commons, and the Applied Statistics Commons

\section{(c) (†) $\ominus$}

This work is licensed under a Creative Commons Attribution-Noncommercial-No Derivative Works 4.0 License.

\section{Recommended Citation}

Aneja, D. R. and Kaushik, L . S. (1998). "BLOCKING IN PARTIAL DIALLEL CROSSES," Conference on Applied Statistics in Agriculture. https://doi.org/10.4148/2475-7772.1286

This is brought to you for free and open access by the Conferences at New Prairie Press. It has been accepted for inclusion in Conference on Applied Statistics in Agriculture by an authorized administrator of New Prairie Press. For more information, please contact cads@k-state.edu. 


\title{
BLOCKING IN PARTIAL DIALLEL CROSSES
}

\author{
D. R. Aneja and L. S. Kaushik \\ C.C.S, Haryana Agricultural University, \\ Hisar (Haryana) -India.
}

\begin{abstract}
Generally the parents are included in the experimental material for combining ability analysis for comparing the performance of crosses with parents and also for calculating heterosis. But unfortunately the parents are ignored for combining ability analysis because of non-availability of analysis procedure. Method of analysis of partial diallel crosses in incomplete blocks for the method -2 of Griffing (1956) has been given.
\end{abstract}

Key words : Partially Balanced Incomplete Block Design, Mating and Environmental Design, partial dialled cross, dual design, n-ary design

\section{Introduction :}

Diallel cross experiments consisting of all possible single crosses are conducted in plant and animal breeding experiments to estimate combining abilities of lines and variance components required for genetical investigations. These experiments whether Complete Diallel Cross (CDC) or Partial Diallel Cross (PDC) have been evaluated using Completely Randomized Design (CRD) or Randomized Block Design (RBD). In most of the cases however, the number of crosses becomes large enough to be included in one single homogeneous block of RBD. It is for this reason that the need of evaluating the PDC in Incomplete Block Design (IBD) was felt by Agarwal and Das (1990), Givecha and Ghosh (1994) and Singh and Hinkelmann (1995).

Work done on PDC mostly pertains to Method -4 of Griffing (1956), wherein parents and reciprocals are ignored. But in actual practice, parents are also included in the experimental material for comparing the performance of crosses with parents and for the calculation of heterosis etc. , but are ignored for combining ability analysis, - a practice which is not free from objection. So to remove these objections on the one hand and to meet the requirement of breeders on the other hand Kaushik and Puri (1985), for the first time, gave the analysis of PDC by including the parents in the sampled crosses. Singh and Hinkelmann (1995) have shown how the same Partially Balanced Incomplete Block Design (PBIB) can be used both for constructing the mating design ( the PDC) and the environmental design to evaluate the crosses of the PDC. It is proposed to show in this paper how the dual design, if used, as an environmental design, is also helpful for evaluating the crosses of the PDC. pertaining to Method -2 of Griffing (1956)

\section{Construction}

It is well known that there exists a relationship between complete diallel crosses (CDC) and Balanced Incomplete Block Design (BIBD) and between partial diallel crosses (PDC) and PBIB designs with two plot blocks. So for the sake of completeness, we define an association scheme and then a PBIB design. 
Definition 1: Association Scheme

Given ' $v$ ' symbols (treatments) $1,2, \ldots v$, a relation satisfying the following conditions is said to be an association scheme with ' $m$ ' classes

(i) Any two treatments are either first or second, ..... or $\mathrm{m}$-th associates, the relation of association being symmetrical : i.e if a treatment $\alpha$ is $i$-th associate of $\beta$, then $\beta$ is also i-th associate of $\alpha$.

(ii) Each treatment $\alpha$ has $n_{i} i$-th associates, the number $n_{i}$ being independent of $\alpha$

(iii) If any two treatments $\alpha$ and $\beta$ are $i$-th associates, then the numbers of treatments that are $j$-th associates of $\alpha$ and $k$-th associate of $\beta$, is $p_{j k}{ }^{i}$ and is independent of the pair of $i$-th associates $\alpha$ and $\beta$.

Given any association scheme for the ' $v$ ' treatments, we can define a PBIB design as follows :

Definition 2 : PBIB design

Given an association scheme with ' $m$ ' classes, we can have a PBIB design if the ' $v$ ' treatments are arranged into 'b' sets (blocks) each of size $k(<v)$ such that

(i) Every treatment occurs at most once in a set.

(ii) Every treatment occurs in exactly ' $r$ ' blocks

(iii) If two treatments $\alpha$ and $\beta$ are $i$-th associates, then they occur together in $\lambda_{i}$ blocks, the number $\lambda_{i}$ being independent of the particular pair of $i$-th associates, $\alpha$ and $\beta$.

Based on different association schemes, PBIB designs are classified into (a) group divisible designs (b) triangular designs (c) latin square type (d) cyclic designs, etc

Definition 3 : Triangular PBIB Design

A PBIB design with two associate classes is said to be triangular if the number of treatments, $v$ $=n(n-1) / 2$ and the association scheme is an array of $n$ rows and $n$ columns with the following properties:

(i) The positions in the principal diagonal are left blank.

(ii) The $n(n-1) / 2$ position above the principal diagonal are filled by the numbers $1,2 \ldots n(n-1) / 2$, corresponding to the treatments.

(iii) The $n(n-1) / 2$ position below the principal diagonal are filled so that the array is symmetrical about the principal diagonal.

(iv) For any treatment ' $i$ ' the first associates are those that occur in the same row or in the same column as $\mathrm{i}$.

We shall illustrate the construction of the design with the help of an example

Consider an association scheme for a triangular PBIB design with, $v=6$

$\begin{array}{cccc}x & 1 & 2 & 3 \\ 1 & x & 4 & 5 \\ 2 & 4 & x & 6 \\ 3 & 5 & 6 & x\end{array}$


The first and second associates of this scheme are

Treatment 1st Associates 2nd Associates

$\begin{array}{lll}1 & 2,3,4,5 & 6 \\ 2 & 1,3,4,6 & 5 \\ 3 & 1,2,5,6 & 4 \\ 4 & 1,2,5,6 & 3 \\ 5 & 1,3,4,6 & 2 \\ 6 & 2,3,4,5 & 1 \\ \text { Taking } & \lambda_{1}=1 \text { and } \lambda_{2}=0 & \end{array}$

where $\lambda_{1}\left(\lambda_{2}\right)$ is the number of times two treatments which are first (2nd) associates, occur together in a block;

the incidence matrix $\mathrm{N}$ of the corresponding PBIB design with block size, $\mathrm{k}=2$; number of blocks, $b=12$; and number of replications, $r=4$, is given by,

$$
\begin{aligned}
& N=\left[\begin{array}{llllllllllll}
1 & 1 & 1 & 1 & 0 & 0 & 0 & 0 & 0 & 0 & 0 & 0 \\
1 & 0 & 0 & 0 & 1 & 1 & 1 & 0 & 0 & 0 & 0 & 0 \\
0 & 1 & 0 & 0 & 1 & 0 & 0 & 1 & 1 & 0 & 0 & 0 \\
0 & 0 & 1 & 0 & 0 & 1 & 0 & 0 & 0 & 1 & 1 & 0 \\
0 & 0 & 0 & 1 & 0 & 0 & 0 & 1 & 0 & 1 & 0 & 1 \\
0 & 0 & 0 & 0 & 0 & 0 & 1 & 0 & 1 & 0 & 1 & 1
\end{array}\right] \\
& \text { Or } \quad N=\left(n_{i j}\right) \quad n_{i j}= \\
& \text { Indicate the number of times i-th treatment }
\end{aligned}
$$

and this $\mathrm{N}$ is also the incidence matrix of the PDC involving 6 parents with sampled crosses as follows:

$$
\begin{array}{llllll}
1 \times 2, & 1 \times 3, & 1 \times 4, & 1 \times 5, & 2 \times 3, & 2 \times 4 \\
2 \times 6, & 3 \times 5, & 3 \times 6, & 4 \times 5, & 4 \times 6, & 5 \times 6
\end{array}
$$

Now in addition to the first associates each line is crossed to its Zeroth associate as well where 0 -th associate is the line itself, then we get design $D_{1}$ (say). Clearly number of sampled crosses in this design will be $p\left(n_{1} / 2+1\right)$ or $p(s / 2+1)$ where ' $n_{1}$ ' is the number of first associates and ' $s$ ' is the number of lines each line is crossed with. So each line will occur $(s+2)$ times. The incidence matrix of this design will be obtained by supplementing with the blocks $(1,1),(2,2) \ldots \ldots(p, p)$. Hence incidence matrix $N^{*}$ is given by: 


$$
N^{.}=\left[\begin{array}{llllllllllllllllll}
1 & 1 & 1 & 1 & 0 & 0 & 0 & 0 & 0 & 0 & 0 & 0 & 2 & 0 & 0 & 0 & 0 & 0 \\
1 & 0 & 0 & 0 & 1 & 1 & 1 & 0 & 0 & 0 & 0 & 0 & 0 & 2 & 0 & 0 & 0 & 0 \\
0 & 1 & 0 & 0 & 1 & 0 & 0 & 1 & 1 & 0 & 0 & 0 & 0 & 0 & 2 & 0 & 0 & 0 \\
0 & 0 & 1 & 0 & 0 & 1 & 0 & 0 & 0 & 1 & 1 & 0 & 0 & 0 & 0 & 2 & 0 & 0 \\
0 & 0 & 0 & 1 & 0 & 0 & 0 & 1 & 0 & 1 & 0 & 1 & 0 & 0 & 0 & 0 & 2 & 0 \\
0 & 0 & 0 & 0 & 0 & 0 & 1 & 0 & 1 & 0 & 1 & 1 & 0 & 0 & 0 & 0 & 0 & 2
\end{array}\right]
$$

Now we have $n_{c}=p(s+2) / 2$ crosses and these are to be evaluated in some IBD or environmental design - the design to be used to evaluate the crosses in environmental conditions. Theoretically speaking these sampled crosses can be accommodated in any incomplete block design in which number of treatments is $p(s+2) / 2$, i.e same as the number of blocks in design $D_{1}$. Specifically we can use dual of the design $D_{1}$ as IBD for PDC. pertaining to method-2 of Griffing (1956). Parameters of this design are $v=n_{c}, b=v=p$ and $k=r+1$

The resultant design happens to be a Partially Balanced $n$-ary design as defined by Tocher (1952). So it can be analysed with the help of PBIBD

The design layout for the above example is as follow:

\begin{tabular}{clllll} 
Block No. & \multicolumn{5}{c}{ Crosses } \\
1 & $1 \times 1$ & $1 \times 2$ & $1 \times 3$ & $1 \times 4$ & $1 \times 5$ \\
2 & $1 \times 2$ & $2 \times 2$ & $2 \times 3$ & $2 \times 4$ & $2 \times 6$ \\
3 & $1 \times 3$ & $2 \times 3$ & $3 \times 3$ & $3 \times 5$ & $3 \times 6$ \\
4 & $1 \times 4$ & $2 \times 4$ & $4 \times 4$ & $4 \times 5$ & $4 \times 6$ \\
5 & $1 \times 5$ & $3 \times 5$ & $4 \times 5$ & $5 \times 5$ & $5 \times 6$ \\
6 & $2 \times 6$ & $3 \times 6$ & $4 \times 6$ & $5 \times 6$ & $6 \times 6$
\end{tabular}

Simply put all those crosses in the same block having some common parent

\section{Model and Estimation :}

We take the following fixed effect model for data in PDC,

$$
\begin{aligned}
Y_{i j l}=\mu & +g_{i}+g_{j}+\beta_{1}+e_{i j l} \\
i & \leq j ; \quad i, j=1,2, \ldots p ; \quad l=1,2 \ldots b
\end{aligned}
$$

where $Y_{\mathrm{ijl}}$ is the yield of the cross involving the lines $\mathrm{i}$ and $\mathrm{j}$ in the l-th block of the design, $g_{i}\left(g_{j}\right)$ refers to the general combining ability (gca) of line $i(i=1,2 \quad \ldots p), \beta_{1}$ is the 1 -th block effect and $\mathrm{e}_{\mathrm{ijl}}$ is the residual error effect comprising of specific combining ability and the experimental error assumed to be distributed as $N\left(0, \sigma^{2}\right)$ The parameters of the model are estimated by the least square theory of estimation and with the usual restrictions $\sum g_{i}$ $=0, \quad \sum \beta_{1}=0$, the normal equations for gca and block effects are as follows : 


$$
\begin{aligned}
& Y_{i . .}=2(s+1) \mu+2(s+1) g_{i}+2 S_{1}(g)+\sum n_{i l} \beta_{1} \\
& B_{1}=(s+1) \mu+(s+1) \quad \beta_{1} \sum n_{i l} g_{i}
\end{aligned}
$$

where $Y_{i .}$ is the yield of all those crosses where the $i$-th line is one of the parents, $B_{1}$ is the yield of the crosses in the l-th block , $S_{1}\left(g_{i}\right)$ is the sum of gca effects of lines which are first associates to the $\mathrm{i}$-th line in the PBIB (mating design), $\mathrm{B}_{1}$ is the effect due to 1 -th block and $n_{i l}$ is the frequency of $i$-th line in l-th block.

From equations (3.2) and (3.3), after solving, we get the following reduced normal equations for $g_{i}{ }^{\prime} s$ :

$$
[2(\mathrm{~s}+1)-\Delta / \mathrm{s}+1] \mathrm{g}_{\mathrm{i}}+\left(2-\pi_{1} / \mathrm{s}+1\right) \mathrm{S}_{1}\left(\mathrm{~g}_{\mathrm{i}}\right)-\pi_{2} \mathrm{~S}_{2}\left(\mathrm{~g}_{\mathrm{i}}\right) / \mathrm{s}+1=\mathrm{Q}_{\mathrm{i}}
$$

where $Q_{i}=Y_{i . .}-1 / s+1 \sum n_{i l} \beta_{1}$

$\Delta=$ column sum of squares of the design matrix, say, $N_{1}=\left(n_{i l}\right)$

$\pi_{1}=\sum n_{i j} n_{m j}, m \neq i, \quad m \& i$ being Ist associates

$\pi_{2}=\sum n_{\mathrm{ij}} n_{\mathrm{mij}}, m \neq i, \quad m \& i$ being IInd associates.

The above equations have the same form as that in the PBIB designs for treatments. These can be solved exactly as in general PBIB design.

After solving (3.4) we get the estimate of $g_{i}$ 's as below

$$
\hat{g}_{t}=\frac{B_{12} Q_{t}-A_{12} S_{1}\left(Q_{t}\right)}{B_{12} A_{11}-A_{12} B_{11}}
$$

where,

$$
\begin{aligned}
& \mathrm{A}_{11}=2(\mathrm{~s}+1)-\left(\Delta-\pi_{2}\right) / \mathrm{s}+1 \\
& \mathrm{~A}_{12}=2-\left(\pi_{1}-\pi_{2}\right) / \mathrm{s}+1 \\
& \mathrm{~B}_{11}=\mathrm{A}_{12}\left(\mathrm{n}_{1}-\mathrm{p}_{11}{ }^{2}\right) \\
& \mathrm{B}_{12}=\mathrm{A}_{11}+\mathrm{A}_{12}\left(\mathrm{p}_{11}{ }^{1}-\mathrm{p}_{11}{ }^{2}\right) \\
& \mathrm{Q}_{\mathrm{i}}=\mathrm{Y}_{\mathrm{i} . .}-\sum \mathrm{n}_{\mathrm{i}} \mathrm{B}_{1} / \mathrm{s}+1
\end{aligned}
$$

$S_{1}\left(Q_{i}\right)=$ the sum of $Q$ values for the first associates of $i$-th treatment.

Also the variance of the difference between gca's of two parents is given by,

$$
V\left(\hat{g}_{i}-\hat{g}_{j}\right)=\frac{2\left(B_{12}+A_{12}\right)}{\boldsymbol{B}_{12} \boldsymbol{A}_{11}-\boldsymbol{A}_{12} \boldsymbol{B}_{11}} \sigma^{2} \quad \begin{gathered}
\text { where } \mathrm{i} \text {-th and } \mathrm{j} \text {-th lines are crossed being } \\
\text { the first associates, }
\end{gathered}
$$




$$
\begin{aligned}
& V\left(\hat{g}_{t}-\hat{g}_{j}\right)=\frac{2 B_{12}}{B_{12} A_{11}-A_{12} B_{11}} \sigma^{2} \quad \begin{array}{l}
\text { where } \mathrm{i} \text {-th and j-th lines are not } \\
\text { second associates, }
\end{array} \\
& \text { S.S } \text { gca }=\sum \hat{g}_{t} Q_{t}=\hat{g}^{\prime} Q \text { with }(\mathrm{p}-1) \mathrm{df} \\
& \text { S.S blocks }=\quad \mathrm{B}_{1}{ }^{2} / \mathrm{s}+1-\mathrm{Y} \ldots{ }^{2} / \mathrm{N} \text { with }(\mathrm{p}-1) \mathrm{df}
\end{aligned}
$$

Example (Contd.). The incidence matrix of the design as given in section 2, is given by,

$$
N_{1}=\left[\begin{array}{llllll}
5 & 1 & 1 & 1 & 1 & 0 \\
1 & 5 & 1 & 1 & 0 & 1 \\
1 & 1 & 5 & 0 & 1 & 1 \\
1 & 1 & 0 & 5 & 1 & 1 \\
1 & 0 & 1 & 1 & 5 & 1 \\
0 & 1 & 1 & 1 & 1 & 5
\end{array}\right]
$$

Here, $\quad \Delta=29, \quad \pi_{1}=14, \quad \pi_{2}=4$

also $\mathrm{p}_{11}{ }^{1}=2, \mathrm{p}_{11}{ }^{2}=4$

hence $A_{11}=5, \quad A_{12}=8 / 5, \quad B_{11}=0$ and $\quad B_{12}=9 / 5$

therefore $V\left(\hat{\mathbf{g}}_{1}-\hat{\mathrm{g}}_{2}\right)=17 \sigma^{2} / 36$ where lines 1 and 2 are first associates, and $\quad V\left(\hat{\boldsymbol{g}}_{1}-\hat{\boldsymbol{g}}_{2}\right)=\sigma^{2} / 4 \quad$ where lines 1 and 6 are second associates.

\section{SUMMARY}

Partial Diallel Crosses (PDC) are based on PBIB designs with two plot blocks. The dual of this PBIB leads to the incomplete block design for PDC ( Singh \& Hinkelmann, 1995) the present paper gives the analysis of PDC corresponding to method-2 of Griffing (1956) in Incomplete Block Design. This amounts to putting all the crosses in one block which have some common parents. The analysis is similar to the general analysis of PBIB designs.

\section{ACKNOWLEDGEMENTS}

The authors are highly thankful to the referees for their valuable suggestions. 


\section{REFERENCES:}

Agarwal, S.C. and Das, M.N. (1990). Incomplete Block Designs for partial diallel crosses. Sankhya B : 75-81.

Givecha, J . and Ghosh, D.K. (1994). Incomplete block designs for complete diallel crosses and their analysis. Journal of Applied Statistics. 21:395-408

Griffing, B. (1956) . Concept of general and specific combining ability in relation to diallel crossing systems. Australian Journal of Biological Sciences. 9: 463-493

Kaushik, L.S. and Puri, P.D. (1985) : Augmented partial diallel crosses based on circulant sample. Biom. J. 27 (4) : 397-403.

Kaushik, L.S. , Puri, P.D. and Mehta, B.D. (1987) : Augmented partial diallel crosses based on two associate class association scheme. Statistica 47 (3): 389-401.

Singh, M. and Hinkelmann, K . (1995). Partial diallel crosses in incomplete blocks Biometrics 51: 1302-1314.

Tocher, K.D. (1952). Design and analysis of block experiments. J. Roy. Stat. Soc., B: 45-100. 